\title{
Neurofilament Protein Abnormalities in PC12 Cells: Comparison with Neurofilament Proteins of Normal Cultured Rat Sympathetic Neurons ${ }^{1}$
}

\author{
VIRGINIA M. -Y. LEE \\ Division of Neuropathology, Department of Pathology and Laboratory Medicine, The University of Pennsylvania School of Medicine, \\ Philadelphia, Pennsylvania 19104.
}

\begin{abstract}
The studies described here characterize abnormalities in the expression of neurofilament (NF) proteins in a clonal rat pheochromocytoma (PC12) cell line as compared with normal NF proteins in cultured rat sympathetic neurons (RSNs).

Cytoskeletal extracts from PC12 cells grown in the presence (PC12 + cells) or absence (PC12- cells) of nerve growth factor (NGF) and from RSNs grown in the presence of NGF were analyzed in nitrocellulose replicas of one- and twodimensional polyacrylamide gels by the immunoblot method using monoclonal antibodies and antiserum to individual NF subunits.

RSNs failed to express the high molecular weight NF subunit (NF200) for the first 10 days in culture although both lower molecular weight NF subunits (NF68 and NF150) were expressed by these cells. At later times in culture, all three NF subunits were present in immunoblots of RSNs. The immunoblot profile of NF proteins in PC12- cells was identical to that of RSNs grown in culture for up to 10 days. Growth of PC12 cells in NGF for up to 3 weeks did not alter this immunoblot profile except that no immunoband corresponding in NF200 was seen and the immunobands corresponding to NF68 and NF150 became more prominent.

These data suggest that abnormalities in NF protein expression in PC12 cells are due to a paucity of NF200 or to the presence of immunochemically altered NF200. PC12 cells are an attractive model system for probing abnormal NF metabolism.
\end{abstract}

A nerve growth factor (NGF)-responsive clonal rat pheochromocytoma cell line (PC12 cells), in which NGF induces many of the phenotypic features of neurons, is used extensively as a model for neural differentiation (Greene and Tischler, 1976, 1982). Recently, we observed that $\mathrm{PC} 12$ cells grown with $(\mathrm{PC} 12+)$ and without (PC12-) physiological amounts of NGF expressed immunoreactive neurofilament (NF) proteins (Lee et al., 1982a; Lee and Page, 1984). Although NGF induced an increase in the expression of NF proteins, the three subunits comprising NFs appeared abnormal in the PC12 cells compared with normal, cultured rat sympathetic neurons (RSNs). Specifically, each NF subunit was, in part, differentially localized within the PC12 cells. The smallest NF subunit or $M_{r}=$

Received January 30, 1985; Revised April 8, 1985;

Accepted April 10, 1985

${ }^{1}$ This work was supported by National Institutes of Health Grant NS 18616. Appreciation is expressed to Ms. C. Page for excellent technical assistance and Ms. M. Obrocka for photographic work. Drs. W. W. Schlaepfer and J. $Q$. Trojanowski have provided helpful comments on this manuscript.
68,000 (NF68) was arranged in juxtanuclear "ball-like" aggregates, whereas the 150,000- and 200,000-dalton (NF150 and NF200, respectively) NF subunits were distributed primarily in a diffuse pattern within the cytoplasm of these cells (Lee et al., 1982a, b). Furthermore, the amount of NF68 induced by NGF in PC12 cells was 5 to 7 times greater than the combined amount of NF150 and NF200 induced by this growth factor (Lee and Page, 1984).

NF expression in developing avian and mammalian neurons has been characterized in vivo. During ontogenesis, the appearance of NF proteins coincides with a switch away from the expression of vimentin filament (VF) protein in precursor cells to the expression of NF proteins in nascent neurons derived from these precursors (Tapscott et al., 1981). However, not all three NF triplet proteins are expressed in synchrony. In the CNS and PNS both NF68 and NF150 are expressed in vivo at an earlier stage of development than is NF200 (Calvert and Anderton, 1982; Shaw and Webber, 1982; Pachter and Liem, 1984; Bennett and DiLullo, 1985). It is therefore unclear to what extent the aberrant expression of NF proteins in PC12 cells diverges from the expression of NF subunits in normal developing neurons in vivo or in vitro.

In the studies described here, the expression of NF triplet proteins by newborn RSNs cultured for different lengths of time in NGF is reported for the first time using NF subunit-specific monoclonal antibodies (MAs) and antisera (AS) (Lee et al., 1982b, 1984; Trojanowski et al., 1985) with the immunoblot method (Towbin et al., 1979). This information is comparcd with data on PC12- and PC12+ cells obtained using the same procedures. Our findings indicate that the developmental expression of NF subunits in RSNs parallels that observed in other neurons: NF200 appears later than NF150 and NF68. Furthermore, although PC12 cells contain NF68 and NF150, no polypeptide corresponding to NF200 is detected in the PC12 cells. We conclude that the neurofilaments in PC12 cells may be abnormal due to a deficiency in the expression of NF200.

\section{Materials and Methods}

PC12 cells and RSNs in cultures. The PC12 cells were grown in plastic culture dishes (Falcon) or on glass coverslips coated with a thin film of air dried rat-tail collagen using culture medium comprised of $85 \%$ RPMI 1640 $5 \%$ fetal calf serum, and $10 \%$ heat-inactivated horse serum as previously described (Lee et al., 1977). PC12 cells grown under these conditions without added NGF are termed PC12-cells. For experiments using NGFtreated PC12 cells, designated here PC12+ cells, $50 \mathrm{ng} / \mathrm{ml}$ of $2.5 \mathrm{~S} \mathrm{NGF}$ were added to the culture medium according to previously established procedures (Lee et al., 1977, 1980, 1982a, 1984). Sympathetic ganglia were dissected from newborn rats and dissociated neuronal cultures were obtained as described previously (Lee et al., 1980). Non-neuronal cells were eliminated from the cultures by adding $10 \mathrm{nM}$ arabinosylcytosine to the culture medium on the second day in culture.

Radiolabeled PC12 cells and RSNs. PC12+ cells and RSNs were radiolabeled metabolically by culturing the cells either in $\left[{ }^{35} \mathrm{~S}\right]$ methionine $(5 \mu \mathrm{Ci} /$ $\mathrm{ml})$ or in $\left[{ }^{3} \mathrm{H}\right]$ glutamic acid $(5 \mu \mathrm{Ci} / \mathrm{ml})$ for $48 \mathrm{hr}$ in complete medium devoid 
of cold methionine or glutamic acid, respectively. Cytoskeletal fractions were prepared from radiolabeled cultured cells as described below.

Perturbation of the cytoskeleton of PC12 cells. Rearrangements in the cytoskeleton of $\mathrm{PC} 12+$ and PC12- cells were induced in some experiments by growing the cells for 1 to 7 days in the presence of $10 \mu \mathrm{g} / \mathrm{ml}$ of leupeptin alone, or in the presence of $10 \mu \mathrm{g} / \mathrm{ml}$ of colchicine for $16 \mathrm{hr}$, with or without the addition of $10 \mu \mathrm{g} / \mathrm{ml}$ of leupeptin for the same amount of time.

Cytoskeletal fractions from rat spinal cord, PC12 cells, and RSNs. Rat NF proteins were extracted from adult rat spinal cords by a simple one-step procedure as reported previously (Schlaepfer et al., 1984). Briefly, fresh spinal cord was rapidly desheathed and homogenized in a 10 -fold dilution $(\mathrm{w} / \mathrm{v})$ of $20 \mathrm{~mm}$ sodium phosphate buffer, $\mathrm{pH} 7.2$, containing $1 \%$ Triton $\mathrm{X}$ 100, $1 \mathrm{M}$ sucrose, $2.5 \mathrm{~mm}$ EDTA, $2.5 \mathrm{~mm}$ EGTA, and $100 \mathrm{~mm} \mathrm{NaCl}$. Contaminating myelin in the lipid pad floating above the supernatant was removed after a 6 -hr centrifugation in a Beckman Ti45 rotor at 100,000 $\times \mathrm{g}$ and again after a second centrifugation overnight. Finally, the pellet was washed free of Triton and sucrose using the buffer described above, minus Triton and sucrose. After a brief centrifugation, the pellet was solubilized in Laemmli sample for SDS-PAGE (Laemmli, 1970) or in $8 \mathrm{M}$ urea for isoelectric focusing.

PC12- cells, PC12 + cells, and cultured RSNs were washed three times with phosphate-buffered saline (PBS) containing $2.5 \mathrm{~mm}$ EGTA. Two to $5 \mathrm{ml}$ of another homogenizing buffer containing $1 \%$ Triton $\mathrm{X}-100,5 \mathrm{~mm}$ EDTA, 5 mM EGTA, $1 \mathrm{~mm}$ magnesium chloride in $0.01 \mathrm{M}$ phosphate buffer, $\mathrm{pH} 6.8$, were added directly to each of the cultures immediately following the last wash with PBS. The cells were scraped from the tissue culture dishes and placed together with the buffer into a ground-glass Duall homogenizer and rapidly homogenized. The homogenates were then centrifuged at 100,000 $\times g$ for $60 \mathrm{~min}$. The soluble proteins were decanted and the Triton-insoluble pellets were washed in the same homogenizing buffer but without Triton These insoluble cytoskeletal fractions were solubilized either in freshly prepared $8 \mathrm{M}$ urea for isoelectric focusing or in Laemmli sample buffer and then boiled for $10 \mathrm{~min}$, centrifuged in a Microfuge, and immediately subjected to SDS-PAGE. The Triton-soluble proteins were recovered by precipitation with a 10 -fold dilution $(\mathrm{v} / \mathrm{v})$ of cold $\left(-20^{\circ} \mathrm{C}\right)$ acetone. These precipitates were washed twice with fresh, cold acetone and dissolved in Laemmli sample buffer.

MAs and AS. One hundred and five MAs from a previously described library of anti-NF MAs produced against individual bovine NF subunits were selected for use in this study (Lee et al., 1982b, 1984; Trojanowski et al., 1985). The specificities of these anti-NF MAs for individual NF subunits extracted from rat spinal cord were determined using the immunoblot method following procedures similar to those already published (Lee et al., 1982, 1984). The specificities of these MAs for rat NF polypeptides are: 73 MAs specific for NF200 only; 20 MAs specific for epitopes shared by NF150 and NF200; 4 MAs specific for NF150 only; 6 MAs specific for NF68; and 2 MAs specific for epitopes shared by NF68 and VF.

MAs to VF protein extracted from bovine lens have also been prepared (Lee et al., 1984). One of these MAs (1.3H9) also recognizes rat VF protein (Lee and Page, 1984), and it was used in the studies described here.

Rat AS to bovine NF triplet proteins were obtained from the immunized rats used for the fusions which resulted in our library of anti-NF MAs. These AS were characterized with respect to their specificities for both bovine and rat NF proteins in the same manner used to characterize the MAs.

Indirect immunofluorescence staining of PC12+ cells and RSNs. NGFtreated $\mathrm{PC} 12+$ cells and RSNs were grown on glass coverslips, fixed in freshly prepared $4 \%$ paraformaldehyde in PBS for $10 \mathrm{~min}$, and permeabilized with $1 \%$ Triton X-100 in PBS for $1 \mathrm{~min}$ and stained for indirect immunofluorescence as described previously (Lee et al., 1982a; Lee and Page, 1984). Rhodamine-labeled anti-rat lg antibodies were purchased from Cappel Laboratories (Cochransville, PA).

Gel electrophoresis and immunoblot procedures. The samples subjected to one-dimensional SDS-PAGE were electrophoresed in $0.75-\mathrm{mm}$ slab gels of $7.5 \%$ acrylamide with $0.4 \%$ or $0.8 \% \mathrm{~N}, \mathrm{~N}^{\prime}$-methylene-bis-acrylamide using the Laemmli gel system (Laemmli, 1970). Transfer of proteins from acrylamide gels to nitrocellulose paper to produce replicas of the gels for immunostaining was conducted according to the methods of Towbin et al. (1979) as modified by Lee et al. (1984). The immunoblot procedure to detect protein bands recognized by the specific binding of AS and MAs to different NF subunits and VF proteins was undertaken as previously reported (Lee et al., 1984)

For the isoelectric focusing studies, cytoskeletal fractions from PC12+ cells or cultured RSNs previously subjected to metabolic radiolabeling with $\left[{ }^{35} \mathrm{~S}\right]$ methionine or $\left[{ }^{3} \mathrm{H}\right]$ glutamic acid were solubilized in $8 \mathrm{M}$ urea and admixed with enriched normal non-radiolabeled rat NF from spinal cord solubilized in $8 \mathrm{M}$ urea. Isoelectric focusing was conducted horizontally using an LKB Multiphor (LKB Instruments, Gaithersburg, MD). Focusing gels were generally
$0.5 \mathrm{~mm}$ thick with a pH gradient of 4 to 6 , and they consisted of $4 \%$ ampholine, $7 \mathrm{M}$ urea, $7.5 \%$ acrylamide, and $4 \mu \mathrm{g} / \mathrm{ml}$ of riboflavin. The isoelectric focusing gels were run for $1.5 \mathrm{hr}$ at $20 \mathrm{~W}$ and at $16^{\circ} \mathrm{C}$. After completion of the isoelectric focusing, the horizontal slab gels were cut into strips, equilibrated with Laemmli sample buffer, and applied immediately to the stacking gel $(3.5 \%)$ above the $7.5 \%$ separating gel for electrophoresis in the second dimension. Upon completion of electrophoresis in the second dimension, the gel was transferred electrophoretically onto nitrocellulose paper and the entire nitrocellulose replica was immunostained with the different anti-NF MAs in the same manner described for one-dimensional immunoblots (Lee et al., 1984). After the immunoreactive proteins were visualized in the nitrocellulose replicas of the two-dimensional gels, these same replicas were allowed to dry, and then the radiolabeled proteins in the replicas were visualized autoradiographically. This allowed the position of the "hot" cytoskeletal proteins in the nitrocellulose sheets to be correlated with the immunobands visualized by the different anti-NF antibodies.

\section{Results}

Indirect immunofluorescence studies. PC12+ cells treated with NGF for 4 weeks and stained with an anti-NF68 MA showed the characteristic juxtanuclear "ball-like" configuration with some neurite staining (Fig. 1A) as reported previously (Lee et al., 1982a; Lee and Page, 1984). In contrast, cultured RSNs treated with NGF for the same length of time and stained with the same MA showed bright fluorescence staining evenly distributed throughout cell bodies and
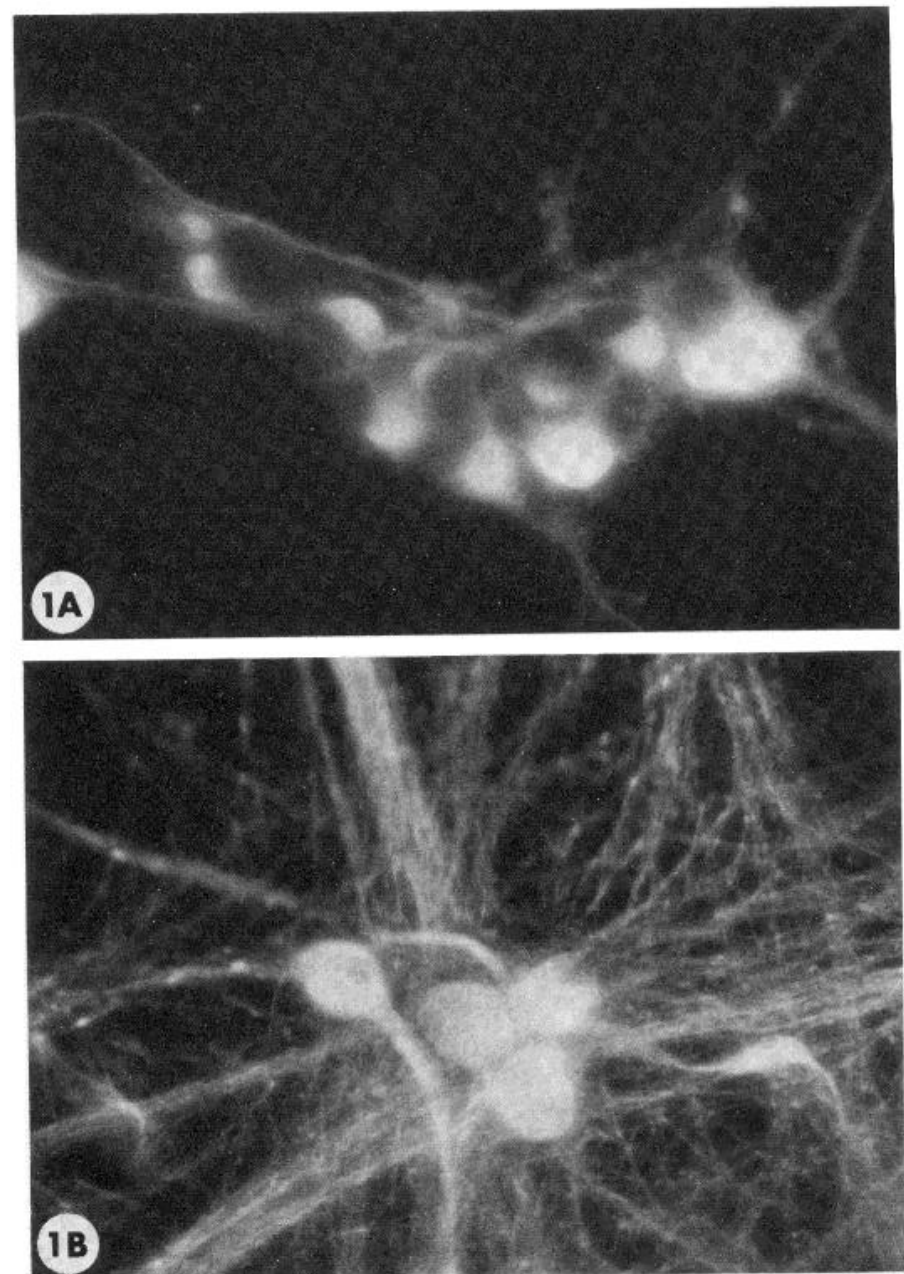

Figure 1. Photomicrographs of $\mathrm{PC} 12+$ cells $(A)$ or cultured RSNs $(B)$ stained by the immunofluorescence method using an MA (SE2) specific for NF68. Juxtanuclear aggregates of NF68 immunoreactivity are seen in the PC12+ cells in agreement with previous work (Lee et al., 1982a), whereas no such aggregates are seen in the RSNs. Neurites are stained with this MA in both cell types, but they are more numerous in the RSN preparation. Magnification $\times 400$. 
in processes (Fig. 1B). No juxtanuclear "ball-like" arrays of immunoreactive NF68 proteins were detected in cultured RSNs. The immunofluorescence staining pattern in cultured RSN cell bodies and neurites seen with the anti-NF150 and anti-NF200 MAs was identical to that observed with the anti-NF68 MA (data not shown). In the

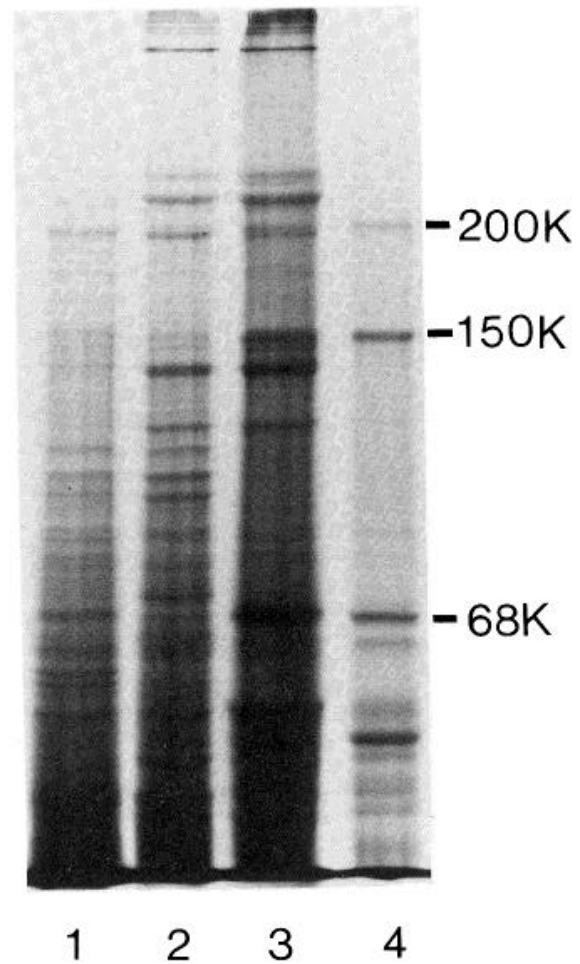

Figure 2. Photograph of a Coomassie blue-stained gel following SDSPAGE to which were applied equal amounts of Triton $\mathrm{X}$-insoluble cytoskeletal extracts from PC12- cells (lane 1), PC12+ cells (lane 2), cultured RSNs (lane 3), and rat spinal cord (lane 4). The NF triplet proteins (NF200, NF150, and NF68) are the three prominent higher molecular weight bands in rat spinal cord. The identity of these bands is defined more specifically in the immunoblots (Figs. 3 to 5 ) prepared from nitrocellulose replicas of similar gels.
PC12+ cells, however, the localization of each of these NF subunits did not overlap with the location of NF68. As observed previously, both for PC12 + cells and PC12- cells (Lee et al., 1982a; Lee and Page, 1984), NF150 and NF200 were distributed throughout the cytoplasm and only rare juxtanuclear "ball-like" aggregates of NF150 and NF200 were seen. VF protein staining using the anti-VF MA in cultured RSNs was prominent initially but diminished and disappeared with time in culture (data not shown). This same anti-VF MA brightly stained the juxtanuclear "ball-like" structures in the PC12+ cells as reported earlier (Lee and Page, 1984).

Analysis of cytoskeletal extracts in Coomassie blue-stained gels. The electrophoretic profile of proteins in the enriched cytoskeletal fractions from $\mathrm{PC12}+$ cells, PC12- cells, and cultured RSNs compared with that from rat spinal cord is shown in Figure 2. In this Coomassie blue-stained electrophoretogram, it is evident that none of the NF subunits or VFs are major components in the cytoskeletal fractions obtained from either the $\mathrm{PC} 12+$ or $\mathrm{PC} 12-$ cells, nor are NF and VF proteins prominent in the extracts from cultured RSNs. Although protein bands with electrophoretic mobilities similar to those of the NF triplet proteins and VF from rat spinal cord are seen in extracts from the cultured cells, the precise molecular identity of the proteins in these bands cannot be determined with certainty in SDSPAGE preparations.

Analysis of Triton X-100-insoluble cytoskeletal extracts in onedimensional immunoblots. In order to specifically identify NF and VF proteins in the electropherograms, immunoblot studies were conducted using the MAs and AS to NF subunits and VF protein in $\mathrm{PC} 12+$ cells, PC12- cells, and cultured RSNs. These preparations were compared with the immunoblot profile of mature rat spinal cord cytoskeletal extracts. In the PC12- cells, NF68, NF150, and VF protein were detected (Fig. 3). NF200 was never seen, even with polyclonal AS raised to NF triplet proteins. The two lower molecular weight NF subunits and VF protein were also detected in extracts of $\mathrm{PC} 12+$ cells. These immunobands became more prominent in PC12+ cells exposured to NGF for longer periods of time (Fig. 3). It is interesting to note that an NF non-triplet immunoband with $M_{\mathrm{r}}=$ $\sim 66,000$ was detected with AS to NF68. This immunoband was also detected with the same AS in extracts from rat spinal cord; it was never detected with any of the anti-NF MAs. Whether or not this immunoband represents a degradative product of NF68 remains to be determined.

The developmental expression of NF subunits in extracts from
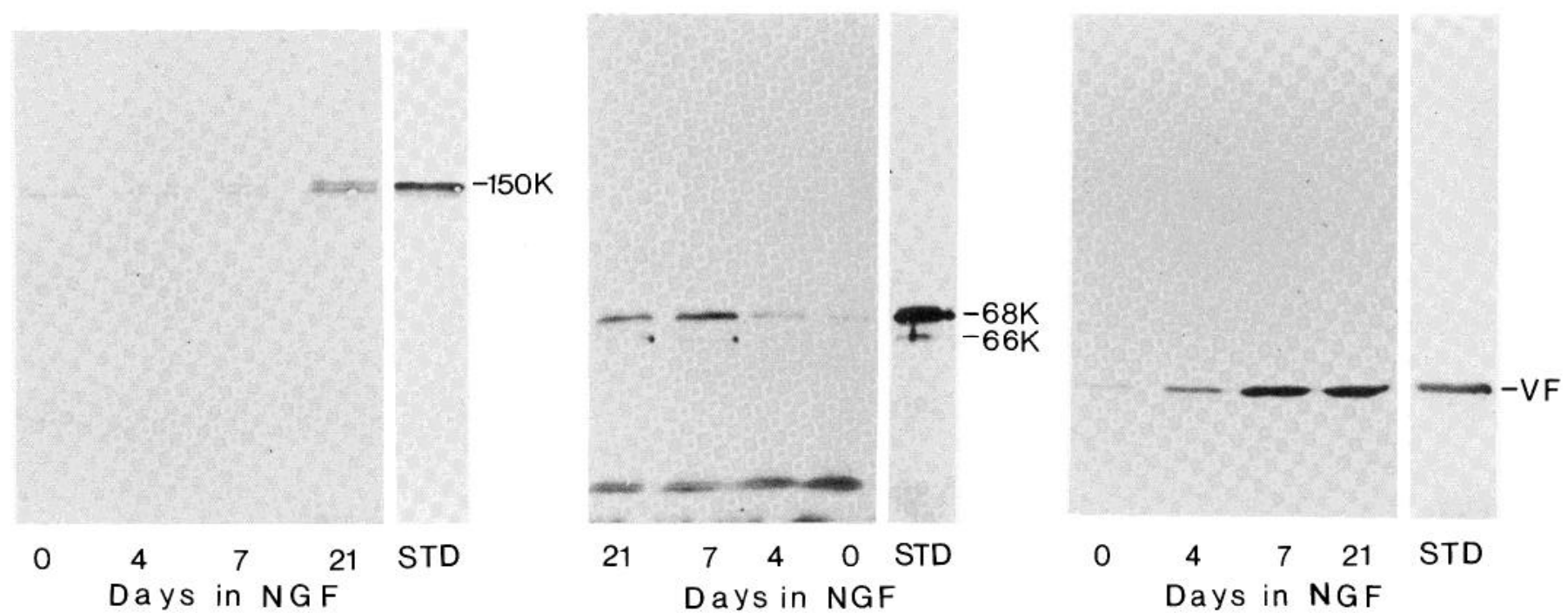

Figure 3. Photographs of nitrocellulose replicas of SDS gels immunostained (from left to right) with an anti-NF150 MA (TA54), an antiserum to NF68, or an MA to VF protein (1.3H9). Each lane of the gels was loaded with equal amounts of Triton X-insoluble cytoskeletal extracts from PC12 cells grown for 0 , 4,7 , and 21 days in NGF as indicated below each replica. The far right lane of each immunoblot (STD) contains Triton-insoluble cytoskeletal extracts from mature rat spinal cord as a control. The immunobands corresponding to NF150, NF68, and VF protein become more prominent as a function of time in NGF. 
cultured RSNs was examined for comparison with the data on the PC12 cells. RSNs were harvested from newborn rats within $24 \mathrm{hr}$ of birth and grown in culture medium with NGF. Cytoskeletal extracts were obtained from these RSNs on the 4th, 7th, and 21st days in culture. After 4 days in culture, both NF68 and NF150, but not NF200, were detected in immunoblots from these cells (Fig. 4A). At 7 days, the immunoblot profile was unchanged from that observed at 4 days except that the 66,000-dalton non-NF triplet protein immunoband became more prominent (Fig. 4B). In addition, NF200 was barely detected in some immunoblot preparations at this time point. By 21 days in culture, all three NF subunits were evident (Fig. $4 C$ ). The intensity of the NF200 immunoband varied somewhat depending upon the MA and AS used to detect it (cf. lanes 1,2, and 5 in Fig. $4 C$ ). In addition, many more presumed NF breakdown products (NF non-triplet proteins) were detected at this time point, especially with the anti-NF AS (cf. lanes 4 and 5 with lanes 1,2, 3, and 6 in Fig. $4 C$ ). For comparison with these data, the immunoblot profile of extracts from adult rat spinal cord using the same MAs and $A S$ is shown in Figure $4 D$. It is noteworthy that the putative NF breakdown products were more prominent in the cytoskeletal fractions isolated from RSNs after 3 weeks in culture with NGF than in the NF preparation from adult rat spinal cord (cf. lane 5 in Fig. $4 \mathrm{C}$ with lane 5 in Fig. 4D).

In order to document further the absence of NF200 in the PC12+ and $\mathrm{PC} 12-$ cells, more than $90 \mathrm{MAs}$ which recognize different epitopes on the NF200 subunit from the rat CSN (Carden et al., 1985) were used. Some of these MAs recognize exclusively NF200 and others recognize epitopes shared by both NF150 and NF200 from the rat. None of these MAs detected an immunoband in the extracts from the PC12 cells which corresponded to NF200 identified with the same MA in the extracts from rat spinal cord (left and right strips, respectively, in Fig. 5, $A$ to $D$ ).

In contrast, NF150 from the PC12 cells is detected by two different anti-NF150 MAs (Fig. 5, $E$ and $F$ ). NF150 from PC12 cells always appears as a doublet. For reasons that are not known, NF150 from rat spinal cord can be a doublet or a single immunoband. Perhaps because of the low quantities of NF150 in the PC12 cells (Lee and Page, 1984) or because of the low avidity of some MAs for their corresponding epitopes, most of the MAs which recognized determinants shared by NF150 and NF200 in normal rat NF were unable to detect NF150 in PC12 cells. In contrast, all of the MAs which recognized NF68 in rat spinal cord also recognized the subunit in immunoblots of PC12 cells (Fig. 5, G and $H$ ).

Although an immunoband corresponding in molecular weight to NF200 was not detected with these MAs or AS, some of these antibodies did recognize immunoreactive non-triplet NF proteins with $M_{\mathrm{r}}=57,000$ to 70,000 in immunoblots from the PC12 cells (Fig. $5 /$ ). Similar non-triplet NF proteins were observed to be derived from NF200 in transected rat sciatic nerves (Schlaepfer et al., 1984). These immunobands are unlikely to correspond to NF200 which has undergone dephosphorylation (Carden et al., 1985).

Since the presence of large quantities of putative NF200 breakdown products in the PC12 cells could reflect unusually active or rapid proteolysis of NF200 following synthesis, PC12 cells were
A

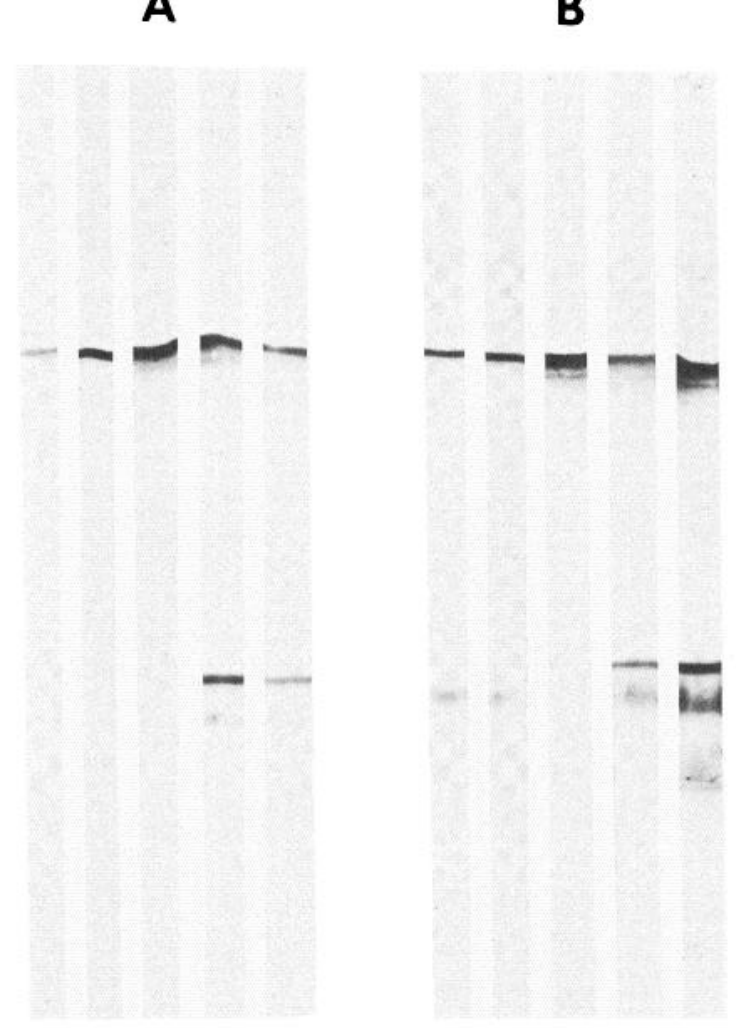

B

$\begin{array}{lllll}1 & 2 & 3 & 4 & 5\end{array}$
C

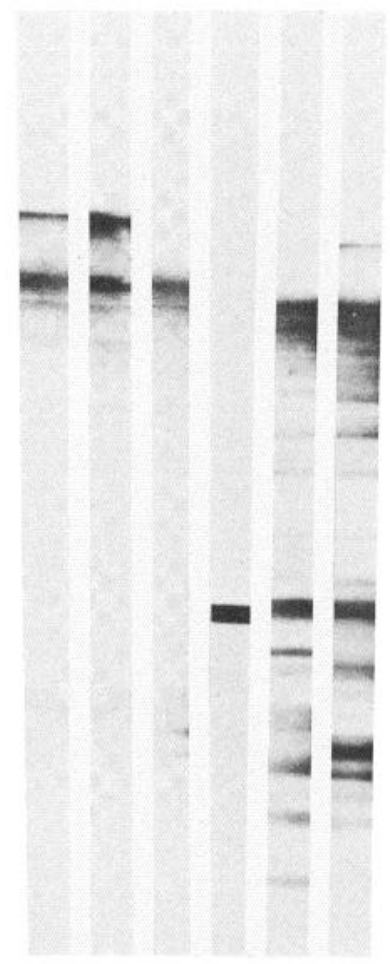

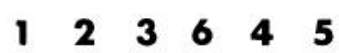

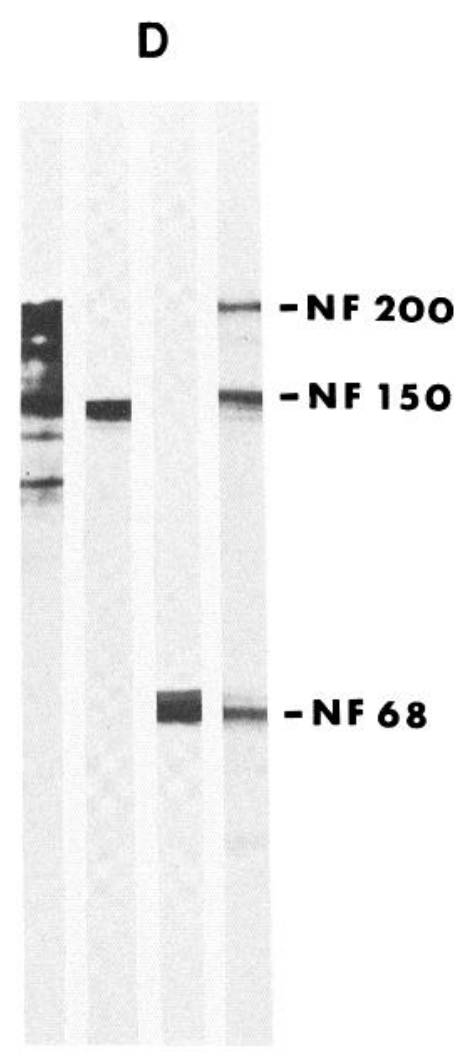

1363

Figure 4. Photographs of strips cut from nitrocellulose replicas of SDS gels containing electrophoresed Triton X-insoluble cytoskeletal extracts from cultured RSNs grown for $4(A), 7(B)$, or $21(C)$ days in NGF. The strips in $D$ were cut from replicas of gels loaded with cytoskeletal extracts from mature rat spinal cord as controls. Each strip identified with the same number was immunostained with the same antiserum or MA. These included OC52, an MA specific for NF150 and NF200 (strip 1); TA12, an MA specific for NF150 and NF200 (strip 2); TA54, and MA specific for NF150 (strip 3); AS specific for NF150 and NF68 (strip 4); AS cocktail which recognizes all three NF triplet proteins (strip 5); and SE2, an MA specific for NF68 (strip 6 ). The immunobands corresponding to the NF triplet proteins are identified as NF200, NF150, and NF68. The molecular weights of the immunobands corresponding to non-triplet NF proteins are not indicated in the figure. 


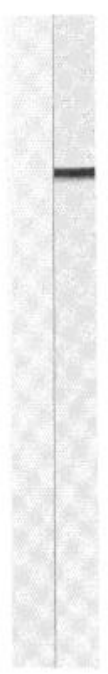

A

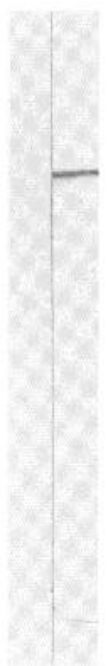

B

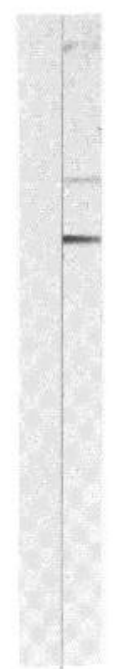

C

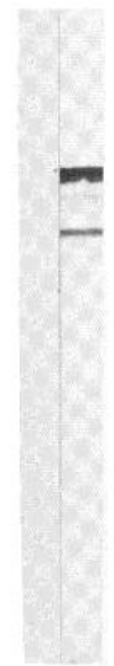

D

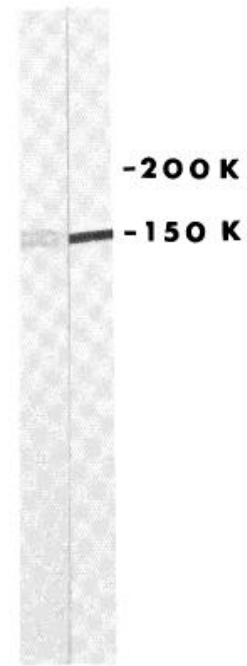

$\mathbf{E}$

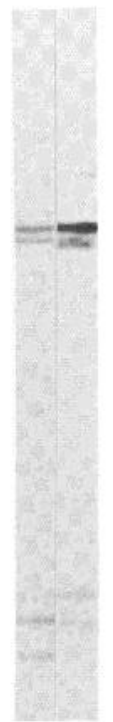

$\mathbf{F}$

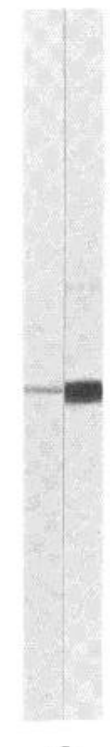

G

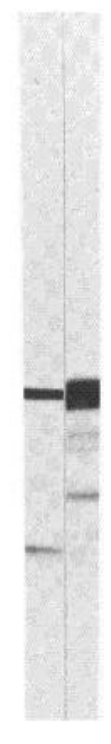

H
Figure 5. Photographs of pairs of strips cut from nitrocellulose replicas of SDS gels containing either electrophoresed, Triton Xinsoluble, cytoskeletal extracts from $\mathrm{PC} 12+$ cells cultured in the presence of NGF for 2 weeks (strips on the left) or similar extracts from mature rat spinal cord (strips on the right). Each pair of strips (identified by letters $A$ to I) was immunostained with the same MA. The MAs and their specificities are: TA51, specific for NF200 (A); TA3, specific for NF200 (B); OC52, specific for both NF200 and NF150 (C); TA12, specific for both NF200 and NF150 (D); TA54, specific for NF150 $(E)$; OC72, specific for NF150 $(F)$; TA66, specific for NF68 $(G)$; SE6, specific for NF68 $(H)$; and TA52, which recognizes NF200 in addition to non-triplet NF proteins which correspond to breakdown products derived from this NF subunit (I). Note the absence of an immunoband in the strips from the PC12+ cells which corresponds to NF200 from rat spinal cord. The gels from which these replicas were made were run for $6 \mathrm{~cm}$ from the stacking gel prior to transfer. grown in the presence of leupeptin (an inhibitor of calcium-activated neutral protease). Alternatively, a variety of protease inhibitors, such as phenylmethylsulfonyl fluoride, L-1-tosylamide-2-phenylethyl chloromethyl ketone, and p-tosyl-L-arginine methyl ester were added to the extraction buffer. These strategies did not alter the immunoblot profile of the PC12 cells. Furthermore, perturbation of the cytoskeleton with colchicine did not affect the immunoblot pattern of extracts from the PC12 cells (data not shown).

Analysis of Triton X-100-soluble cytoskeletal extracts in onedimensional immunoblots. When the Triton $\mathrm{X}$-100-soluble fractions from the PC12 cells and RSNs were analyzed with the same procedures and antibodies used to study the Triton X-100-insoluble fractions, several non-triplet NF protein immunobands were seen in the PC12 cells. A single 66,000 -dalton band was detected by AS to NF68 (data not shown). Material weakly immunoreactive with this antiserum was also observed running at the dye front. In addition, an anti-NF200 MA (TA52) detected major non-triplet immunobands with $M_{\mathrm{r}}=57,000$ to 66,000 . A less prominent non-triplet immunoband with $M_{\mathrm{r}}=\sim 40,000$ was also observed. Interestingly, the 70,000 - dalton species detected in the Triton-insoluble fraction by the same MA is absent from the Triton-soluble fraction. Triton $X-100$-soluble immunobands were never seen in extracts from rapidly processed cultured RSNs or normal rat spinal cord.

Analysis of Triton X-100-insoluble cytoskeletal extracts in twodimensional immunoblots. NF68 and NF150 in the PC12 cells were compared with the analogous subunits from rat spinal cord in twodimensional immunoblots and autoradiograms. Accordingly, immunoblots were performed on $\left[{ }^{35} \mathrm{~S}\right]$ methionine cytoskeletal extracts from PC12+ cells admixed with "cold" cytoskeletal extracts from rat spinal cord subjected to two-dimensional SDS-PAGE. Autoradiography was then performed on these immunoblot preparations. The results of these experiments are seen in Figure 6. Autoradiograms prepared from the nitrocellulose replicas of these two-dimensional gels reveal that NF68 and NF150 have the isoelectric points and electrophoretic mobilities which correspond to normal rat NF68 and NF150 (Fig. 6, $A$ and C). When the nitrocellulose replicas from which these autoradiograms were prepared were immunostained with either an anti-NF150 or an anti-NF68 MA (Fig. 6, $B$ and D, respec- 

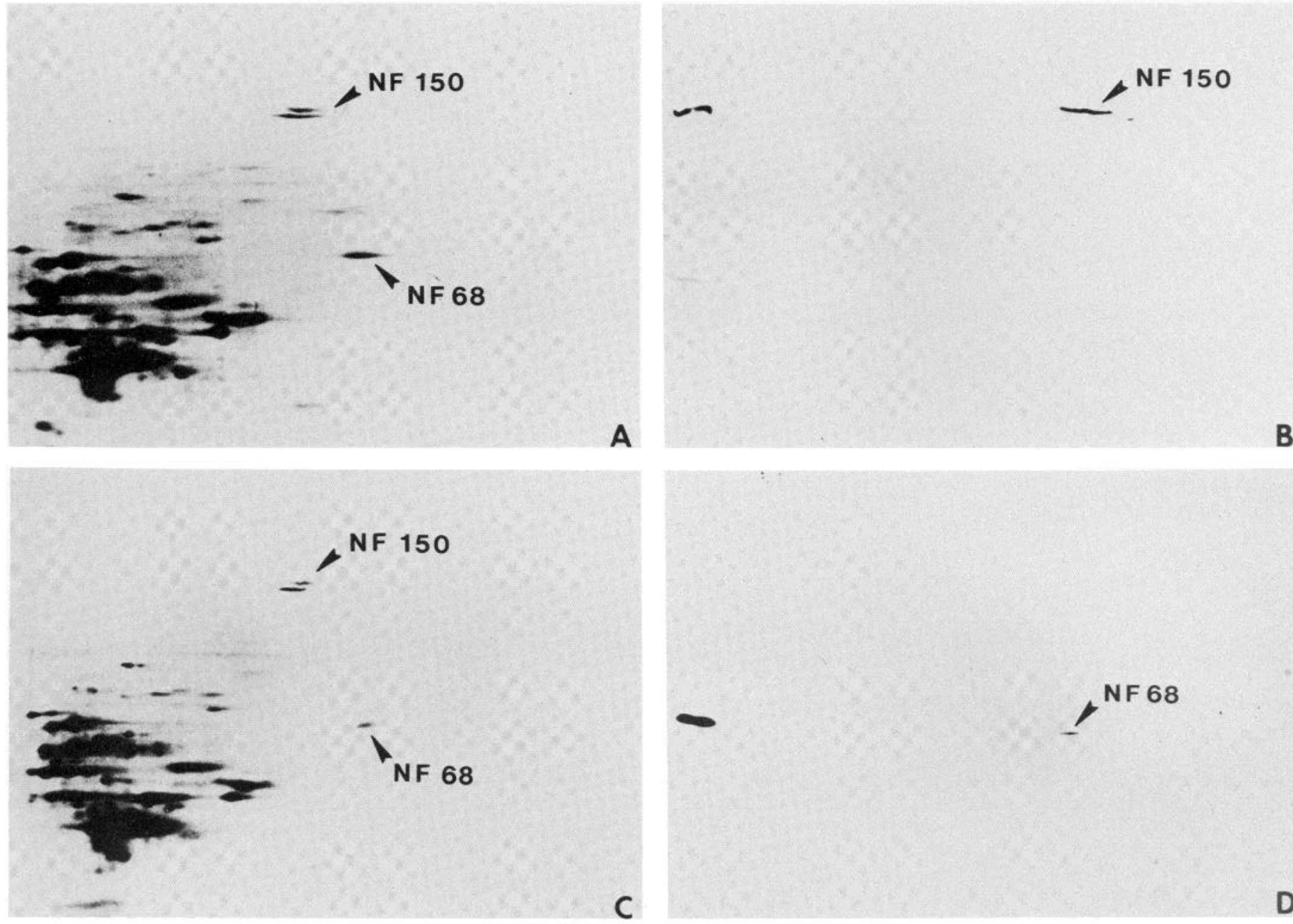

Figure 6. Photographs of autoradiograms $(A$ and $C$ ) prepared from nitrocellulose replicas $(B$ and $D)$ prepared from two-dimensional gels which contained $\left[{ }^{35}\right.$ S]methionine-labeled cytoskeletal extracts from PC12+ cells and cold cytoskeletal extracts from mature rat spinal cord. Radiolabeled bands corresponding to NF150 and NF68 are seen in the autoradiograms in addition to other radiolabeled cytoskeletal proteins. The nitrocellulose replicas were immunostained with an MA specific for NF150 (OC72 in B) or an MA specific for NF68 (TA66 in D). The lane at the left in each of the immunoblots contains cold cytoskeletal extracts from rat spinal cord run only in the second dimension as a control. Note that, although extracts from both rat spinal cord and the PC12+ cells are present in the sheets of nitrocellulose, only one immunoband is present in each two-dimensional immunoblot.

tively), only one immunoband was seen in each nitrocellulose replica. Rat spinal cord NF68 and NF150 were run separately only in the second dimension of the SDS-PAGE as internal controls for the immunoblot preparations. These immunoblots, when viewed with the corresponding autoradiograms, establish that radiolabeled NF68 and NF150 from the PC12+ cells correspond in position to cold NF68 and NF150 from rat spinal cord present together with $\mathrm{PC} 12+$ cell-derived NF68 and NF150 in the nitrocellose replicas.

Although the autoradiogram showed PC12+ cell-derived NF150 as a doublet, in the immunoblot it was seen as one immunoband. This is consistent with the behavior of this NF subunit in other experiments in which radiolabeled NF150 in autoradiograms and immunoreactive NF150 in immunoblots sometimes migrate as a doublet and at other times as a single band.

In none of the autoradiograms performed on two-dimensional gel replicas of $\left[{ }^{35} \mathrm{~S}\right]$ methionine-labeled $\mathrm{PC} 12+$ cell cytoskeletal proteins was there evidence of a band corresponding to NF200. However, since NF200 contains low quantities of methionine but high amounts of glutamic acid (Hogue-Angeletti et al., 1982), $\left[{ }^{3} \mathrm{H}\right]$ glutamic acid was used in other experiments to metabolically label the cytoskeletal proteins of $\mathrm{PC} 12+$ cells. The autoradiograms prepared from gels following two-dimensional SDS-PAGE of $\left[{ }^{3} \mathrm{H}\right]$ glutamic acid-labeled cytoskeletal fractions isolated from $\mathrm{PC} 12+$ cells showed no radiolabeled bands corresponding to NF200 (data not shown).

In other experiments, cultured RSNs were similarly labeled with $\left[{ }^{3} \mathrm{H}\right]$ glutamic acid, and cytoskeletal extracts from these cells as well as "cold" cytoskeletal extracts from rat spinal cord were subjected to two-dimensional SDS-PAGE followed by transfer of the separated proteins to nitrocellulose paper. Immunoblots and autoradiograms prepared from these nitrocellulose replicas of the two-dimensional gels showed that NF200, NF150, and NF68 derived from cultured RSNs were present and that they co-localized in the immunoblots with their counterparts extracted from rat spinal cord (data not shown).

\section{Discussion}

The studies described here indicate that NF triplet proteins extracted from $\mathrm{PC} 12+$ cells, cultured RSNs, and rat spinal cord are nearly identical with one important exception: a polypeptide corresponding to rat spinal cord NF200 and RSN NF200 is not detectable in the PC12+ or PC12- cells. The PC12 cell line thus provides a unique model system for probing the biological consequences to a cell of the failure to normally express a integral subunit of the 
intermediate filaments of neurons (Schlaepfer and Freeman, 1978; Schlaepfer et al., 1981).

Although the expression of NF subunits as studied with anti-NF antibodies has been reporled to be abnormal in a number of different neoplastic and non-neoplastic diseases affecting neurons (Lee et al., 1982a; Gambetti et al., 1983; Goldman et al., 1983; Selkoe et al., 1983; Trojanowski et al., 1984b), the nature of these abnormalities is poorly understood. The present work suggests that at least one form of abnormal NF expression, e.g., the aggregation of NF proteins into "ball-like" arrays in neoplastic PC12 cells (Lee et al., 1982a; Lee and Page, 1984), may in part be ascribed to a deficiency in the expression of one of the three NF subunits, i.e., NF200.

The data reported here indicate that, although NGF-treated PC12 cells are known to express many of the phenotypic features of differentiated neurons (Greene and Tischler, 1982), both PC12cells and PC12+ cells fail to express all three NF subunits. Not only is a polypeptide which corresponds to NF200 in cultured RSNs and mature rat spinal cord absent from the PC12 cells, previous studies have demonstrated a relative quantitative scarcity of NF150 in these cells (Lee and Page, 1984). At present it is controversial whether or not all neurons express each of the NF triplet proteins (Shaw et al., 1981; Dahl, 1983; Hirokawa et al., 1984; Trojanowski et al., 1985). For this reason the NF subunits of PC12 cells were compared with those present in normal counterparts of these cells, i.e., cultured RSNs. As shown earlier with monospecific anti-NF AS (Lee et al., 1982a) and here with MAs to individual NF subunits, RSNs cultured under the same conditions as the PC12+ cells do express all three NF subunits and they do not contain "ball-like" aggregates of immunoreactive NF proteins. Thus, these "ball-like" aggregates are not likely to be an artifact of the tissue culture conditions. This interpretation is supported by the recent in situ detection of similar "ball-like" aggregates of NF proteins in human pheochromocytomas (Trojanowski et al., 1984b) and by the recent demonstration that cultured, normal bovine adrenal chromaffin cells contain all NF triplet proteins and do not contain aggregates of these polypeptides (Bader et al., 1984).

Although it is attractive to consider that the failure to express NF200 is the only factor causally related to the abnormal expression of NF proteins in the PC12 cells, this cannot be the complete explanation. In development, the expression of NF200 lags behind that of NF68 and NF150 in the absence of demonstrable aggregates of NF proteins in immunofluorescence studies (Bennett and DiLullo, 1985). The lag in NF200 expression appears to be a general feature of the programs which determine the developmental expression of NF proteins in the CNS and PNS. It is shown here for the first time that this same program can be duplicated in vitro using cultured RSNs from neonatal rats. Under these conditions, a similar lag in NF200 expression was observed in cultured RSNs, but no aggregates of NF proteins were seen.

It is also not possible to ascribe the aggregates of NF proteins exclusively to the mechanisms which allow the emergence of the neoplastic phenotype despite the detection of similar aggregates in pheochromocytomas studied in vivo and in vitro. "Ball-like" accumulations of NF immunoreactivity have been seen in the normal pituitary gland (Trojanowski et al., 1984a) and in non-neoplastic neuronal diseases such as idiopathic Parkinson's disease (Goldman et al., 1983). Furthermore, in another clonal neoplastic cell line, the human embryonal carcinoma (EC) cell line, it is possible to induce the expression of the neuronal phenotype, including all three NF subunits, in a subpopulation of these neoplastic cells with retinoic acid (V. M. - Y. Lee and P. W. Andrews, 1986). In these transformed cells no aggregates of NF polypeptides are seen. For unknown reasons, the expression of NF proteins in the EC cells and in the PC12 cells is stimulus specific; retinoic acid does not induce NF protein expression in PC12 cells, and NGF does not induce the expression of these polypeptides in the EC cells (V. M. $-Y$. Lee, unpublished observation).

In view of the foregoing, then, to what may the NF protein abnormalities in the PC12 cells be ascribed? The answer to this question requires further study. For example, the absence of a polypeptide which co-migrates with NF200 of cultured RSNs or rat spinal cord in the PC12 cells is not conclusive evidence for the complete absence of this NF subunit. The demonstration of intracytoplasmic immunofluorescence in the PC12 cells with NF200specific AS and MAs, together with the identification of low molecular weight immunobands with anti-NF200 MAs in these and previous studies (Lee et al., 1982a; Lee and Page, 1984), indicates that some form of NF200 is expressed by the PC12 cells. These low molecular weight non-triplet NF proteins are similar to those observed following sciatic nerve transection in vivo (Schlaepfer et al., 1984) or following calcium-mediated degradation of sciatic nerve in vitro (Schlaepfer et al., 1985). We have also observed a similar profile of NF protein breakdown products during ontogensis at a time when the organism is eliminating the excess neurons generated early in the development (V. M. -Y. Lee, unpublished observation). It is therefore possible that NF200 is synthesized by the PC12 cells in a normal form and in appropriate quantities, but that it undergoes abnormally rapid proteolysis.

Alternatively, normal NF200 may be synthesized by the PC12 cells, but the PC12 cells may lack the appropriate enzymes or cofactors which permit this polypeptide to undergo normal posttranslational modifications. For example, NF200 is heavily phosphorylated (Shecket and Lasek, 1982; Julien and Mushynski, 1983) and dephosphorylated NF200 subunits are immunochemically and biochemically different from their phosphorylated counterparts (Sternberger and Sternberger, 1983; Carden et al., 1985). Although the functional significance of the phosphorylation of NF200 is unknown, it is conceivable that NF200 phosphorylation plays a crucial role in the putative cross-linking properties of this subunit. Our failure to detect NF200 in a form which corresponds to NF200 in cultured RSNs and rat spinal cord may not be due to the complete absence of this subunit. Instead, this may reflect the presence of "nascent" (unphosphorylated) NF200 which is not immunoreactive with our anti-NF200 MAs, most of which fail to detect NF200 following dephosphorylation (Carden et al., 1985). Since dephosphorylated NF200 has a lower apparent molecular weight in SDS-PAGE when stained with Coomassie blue (Carden et al., 1985), "nascent" (unphosphorylated) NF200 could escape detection in gels stained with nonspecific protein stains.

Fulure sludies will allermpl to determine which of these, or perhaps other, possibilities account for the abnormal expression of NF proteins in PC12 cells. Such studies could contribute insights into NF protein abnormalities seen in other neuronal disorders which specifically afflict the neuronal cytoskeleton.

Note added in proof: Since the submission of this paper, additional studies using newly prepared MAs to dephosphorylated rat NF200 indicate that PC12 cells contain dephosphorylated NF200 but not phosphorylated NF200 as detected by both indirect immunofluorescence and immunoblot techniques.

\section{References}

Bader, M. F., E. Georges, W. E. Mushynski, and J. M. Trifaro (1984) Neurofilament proteins in cultured chromaffin cells. J. Neurochem. 43 : 1180-1193.

Bennett, G. S., and C. DiLullo (1985) Transient expression of a neurofilament protein by replicating cells of the embryonic chick brain. Dev. Biol. 107 . $107-127$

Calvert, R., and B. H. Anderton (1982) In vivo metabolism of mammalian neurofilament polypeptides in developing and adult rat brain. FEBS Lett. 145: 171-175.

Carden, M. J., W. W. Schlaepfer, and V. M. -Y. Lee (1985) The structure, biochemical properties and immunogenicity of neurofilament peripheral regions are determined by phosphorylation state. J. Biol. Chem. 260: 9805-9817

Dahl, D. (1983) Immunohistochemical differences between neurofilaments in perikarya, dendrites and axons. Immunofluorescence study with antisera raised to neurofilament polypeptides (200K, $150 \mathrm{~K}$ and $70 \mathrm{~K})$ isolated by anion exchange chromatography. Exp. Cell Res. 149: 397-408. 
Gambetti, P., L. Autilio-Gambetti, G. Perry, G. Shecket, and R. C. Crane (1983) Antibodies to neurofibrillary tangles of Alzheimer's disease raised from human and animal neurofilament fractions. Lab. Invest. 49: 430-435.

Goldman, J. E., S. H. Yen, F. -C. Chiu, and N. S. Peress (1983) Lewy bodies of Parkinson's disease contain neurofilament antigens. Science 221: 1082-1084.

Greene, L. A., and A. S. Tischler (1976) Establishment of a monoadrenergic clonal line of rat adrenal pheochromocytoma cells which respond to nerve growth factor. Proc. Natl. Acad. Sci. U. S. A. 73: 2424-2428.

Greene, L. A. and A. S. Tischler (1982) PC12 pheochromocytoma cells in neurobiological research. Adv. Cell. Neurobiol. 3: 373-414

Hirokawa, N., M. A. Glicksman, and M. B. Willard (1984) Organization of mammalian neurofilament polypeptides within the neuronal cytoskeleton. J. Cell Biol. 98: 1523-1536.

Hogue-Angeletti, R. A., H. -L. Wu, and W. W. Schlaepfer (1982) Preparative separation and amino acid composition of neurofilament triplet proteins. $J$. Neurochem. 38: 116-120.

Julien, J. -P., and W. E. Mushynski (1983) The distribution of phosphorylation sites among identified proteolytic fragments of mammalian neurofilaments. J. Biol. Chem. 258: 4019-4025.

Laemmli, U. K. (1970) Cleavage of structural proteins during the assembly of bacteriophage T4. Nature 227: 680-685.

Lee, V., M. L. Shelanski, and L. A. Greene (1977) Specific neural and adrenal medullary antigens detected by antisera to clonal PC12 pheochromocytoma cells. Proc. Natl. Acad. Sci. U. S. A. 74: 5021-5025.

Lee, V., L. A. Greene, and M. L. Shelanski (1980) Characterization of antisera raised against cultured rat sympathetic neurons. Neuroscience 5: 22392245.

Lee, V., J. Q. Trojanowski, and W. W. Schlaepfer (1982a) Induction of neurofilament triplet proteins in PC12 cells by nerve growth factor. Brain Res. 238: 169-180.

Lee, V. M. -Y., and P. W. Andrews (1986) Differentiation of NT2/D1 clonal human embryonal carcinoma cells into neurons involves induction of all three neurofilament proteins. J. Neurosci., in press.

Lee, V.M. - Y., and C. Page (1984) The dynamics of nerve growth factorinduced neurofilament and vimentin filament expression and organization in PC12 cells. J. Neurosci. 4: 1705-1714.

Lee, V. M. -Y., H. -L. Wu, and W. W. Schlaepfer (1982b) Monoclonal antibodies recognize individual neurofilament triplet proteins. Proc. Natl. Acad. Sci. U. S. A. 79: 6089-6092.

Lee, V. M. -Y., C. D. Page, H. -L. Wu, and W. W. Schlaepfer (1984) Monoclonal antibodies to gel excised glial filament protein and their reactivities with other intermediate filament proteins. J. Neurochem. 42 . 25-32.

Pachter, J. S., and R. K. H. Liem (1984) The differential appearance of neurofilament triplet polypeptides in the developing rat optic nerve. Dev Biol. 103: 200-210.

Schlaepfer, W. W., and L. A. Freeman (1978) Neurofilament proteins of rat peripheral nerve and spinal cord. J. Cell Biol. 78: 653-662.

Schlaepfer, W. W., V. Lee, and H. -L. Wu (1981) Assessment of immunological properties of neurofilament triplet proteins. Brain Res. 226: 259-272.

Schlaepfer, W. W., C. Lee, J. Q. Trojanowski, and V. M. -Y. Lee (1984) Persistence of immunoreactive neurofilament protein breakdown products in rat sciatic nerve. J. Neurochem. 43: 857-864.

Schlaepfer, W. W., C. Lee, V. M. -Y. Lee, and U. -J. P. Limmerman (1985) An immunoblot study of neurofilament degradation in situ and during calcium activated proteolysis. J. Neurochem. 44: 502-519.

Selkoe, D., Y. Ihara, C. Abraham, C. G. Rasool, and A. H. McCluskey (1983) Biochemical and immunocytochemical studies of Alzheimer paired helical filaments. In Biological Aspects of Alzheimer's Disease, R. Katzman, ed., pp. 125-135, Cold Spring Harbor Laboratory, New York.

Shaw, G., and K. Weber (1982) Differential expression of neurofilament triplet proteins in brain development. Nature 298: 277-279.

Shaw, G., M. Osborn, and K. Weber (1981) An immunofluorescence microscopical study of the neurofilament triplet proteins, vimentin and glial fibrillary acidic protein within the adult rat brain. Eur. J. Cell Biol. 26: 6882.

Shecket, G., and R. J. Lasek (1982) Neurofilament protein phosphorylation. J. Biol. Chem. 257: 4788-4795.

Sternberger, L. A., and N. H. Sternberger (1983) Monoclonal antibodies distinguish phosphorylated and nonphosphorylated forms of neurofilaments in situ. Proc. Natl. Acad. Sci. U. S. A. 80: 6126-6130.

Tapscott, S. J., G. S. Bennett, and H. Holtzer (1981) Neuronal precursor cells in the chick neural tube express neurofilament proteins. Nature 292: 836838.

Towbin, H., T. Staehelin, and J. Gordon (1979) Electrophoretic transfer of proteins from polyacrylamide gels to nitrocellulose sheets: Procedure and some applications. Proc. Natl. Acad. Sci. U. S. A. 76: 4350-4353.

Trojanowski, J. Q., D. Gordon, M. Obrocka, and V. M. -Y. Lee (1984a) The developmental expression of neurofilament and glial filament proteins in the human pituitary gland: An immunohistochemical study with monoclonal antibodies. Dev. Brain Res. 13: 229-239.

Trojanowski, J. Q., V. M. -Y. Lee, and W. W. Schlaepfer (1984b) An immunohistochemical study of human central and peripheral nervous system tumors with monoclonal antibodies against neurofilaments and glial filaments. Human Pathol. 15: 248-257.

Trojanowski, J. Q., M. Obrocka, and V. M. -Y. Lee (1985) Distribution of bovine neurofilament subunits in neurons and neuronal processes: Immunohistochemical studies of bovine cerebellum with subunit specific monoclonal antibodies. J. Histochem. Cytochem. 33: 557-563. 